\title{
Duodenal metastasis of malignant melanoma observed by magnification endoscopy
}

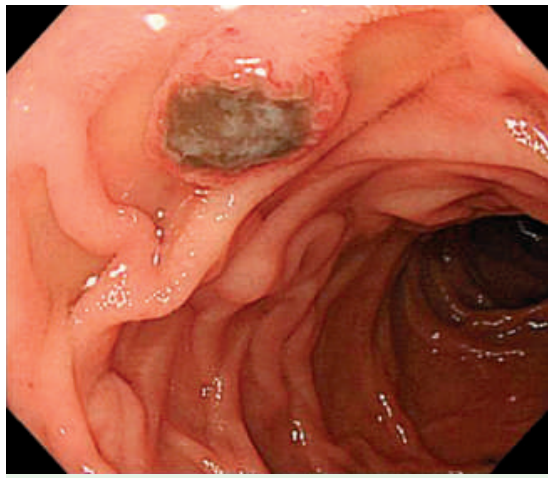

Fig. 1 Endoscopy showed a black, depressed-type tumor in the descending duodenum. It had a "bull's eye" appearance.

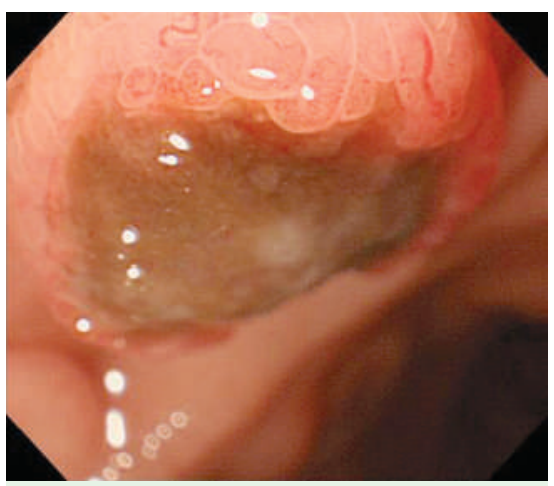

Fig. 2 Magnification endoscopy revealed the smooth surface of the lesion and the surrounding villi.

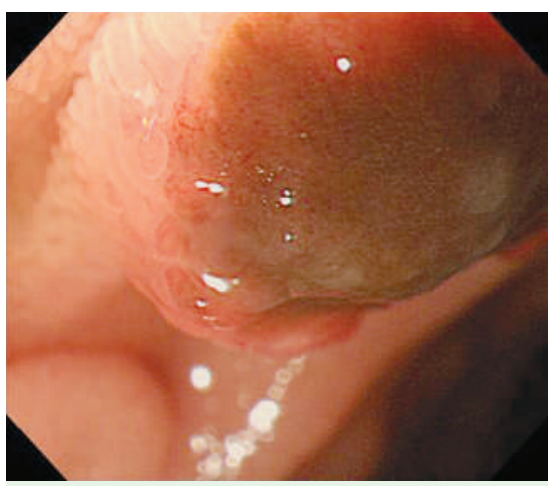

Fig. 3 Very smooth surface of the lesion as shown by magnification endoscopy.

Although malignant melanoma is the most common source of metastasis to the gastrointestinal tract, the features of these metastases as viewed by magnification endoscopy have not been reported.

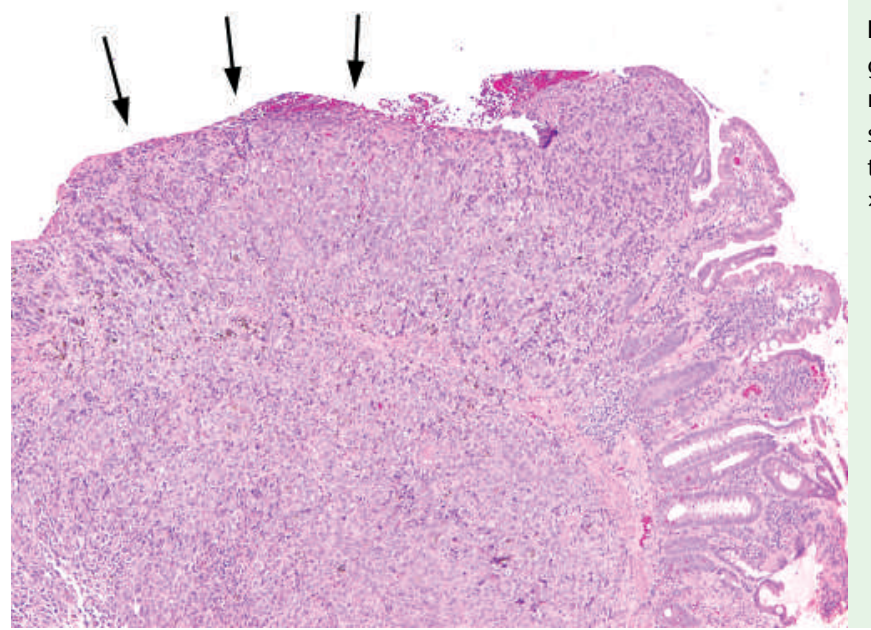

Fig. 4 Photomicrograph of biopsy specimen showing the very smooth surface of the tumor (arrows) (H\&E, $\times 40)$.

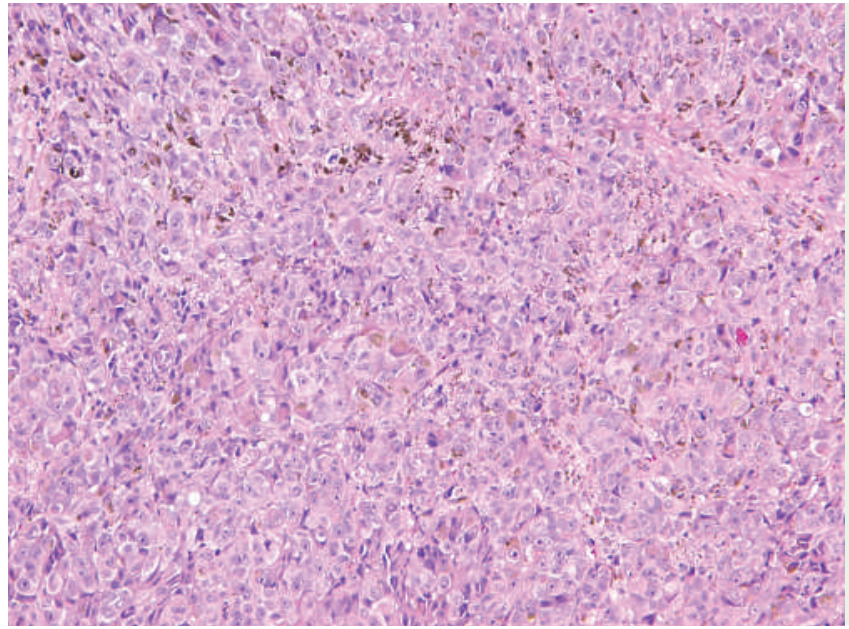

Fig. 5 Photomicrograph of biopsy specimen showing that many malignant melanoma cells had a large amount of brown pigment $(\mathrm{H} \& \mathrm{E}, \times 100)$.

A 77-year-old man whose right great toe had been amputated 3 years previously due to malignant melanoma underwent endoscopy because he was anemic. Multiple black, depressed lesions $(1-5 \mathrm{~mm}$ in diameter) with a "bull's eye" appearance were viewed in the descending duodenum ( $\bullet$ Fig. 1). Under magnification, the surface of these lesions was smooth ( $\bullet$ Fig. 2 and 3), and histological examination of a biopsy specimen ( $\bullet$ Fig. 4 ) revealed tumor cells full of brown pigment ( $\bullet$ Fig. 5). Additional sites of metastasis were found in the ascending colon (by colonoscopy) and in the pulmonary hilar lymph node (by CT). Because of appetite loss, the patient underwent gastrointestinal endoscopy again 2 months later. Increased numbers of black, depressed lesions were seen, larger than before, and tiny black spots viewed under magnification showed a similar smooth surface (๑ Fig. 6).

A diagnosis of malignant melanoma - a frequent source of metastatic disease in the gastrointestinal tract $[1,2]$ - requires identification of melanoma features that distinguish it from other tumors. The use of magnification endoscopy for this purpose in the upper gastrointestinal tract is increasingly common. In the duodenum, Badreldin et al. suggested that zoom endoscopy is valuable in assessing the degree of villous atrophy in celiac disease [3]. Magnified endoscopic views of early duodenal carcinoma [4], as well as duodenal metastasis of malignant melanoma (here), were found to correspond accurately with histopathological findings. We conclude that magnification endosco- 


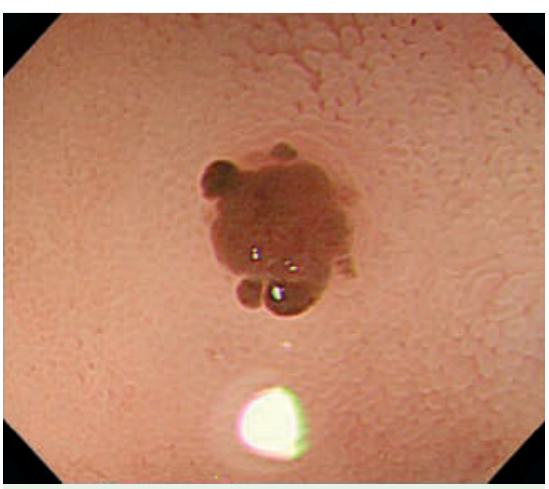

Fig. 6 Magnification endoscopy revealed that a tiny black spot had a smooth surface.

py may be useful, prior to biopsy, for distinguishing features of gastrointestinal metastases of malignant melanoma, such as duodenal melanosis and pseudomelanosis.

Endoscopy_UCTN_Code_CCL_1AB_2AZ_3AB
K. Tanaka ${ }^{1}$, H. Toyoda ${ }^{1}$, Y. Hamada ${ }^{2}$, M. Aoki², R. Kosaka' ${ }^{2}$, T. Noda ${ }^{2}$, M. Katsurahara ${ }^{2}$, M. Nakamura², K. Ninomiya ${ }^{2}$, H. Inoue ${ }^{2}$, I. Imoto

${ }^{1}$ Department of Endoscopic Medicine, Mie University School of Medicine, Tsu, Japan

2 Department of Gastroenterology, Mie University School of Medicine, Tsu, Japan

\section{References}

1 Kadakia SC, Parker A, Canales L. Metastatic tumors of the upper gastrointestinal tract: endoscopic experience. Am J Gastroenterol 1992; 87: 1418 - 1423

2 Blecker D, Abraham S, Furth EE. Melanoma in the gastrointestinal tract. Am J Gastroenterol 1999; 94: 3427-3433

3 Badreldin R, Barrett P, Wooff DA, Mansfield J et al. How good is zoom endoscopy for assessment of villous atrophy in coeliac disease? Endoscopy 2005; 37: 994-998

4 Tanaka K, Toyoda H, Inoue H et al. Depressed type early duodenal carcinoma (carcinoma in situ) observed by enhanced magnification endoscopy. Endoscopy In press 2007
Bibliography

DOI $10.1055 / \mathrm{s}-2007-966566$

Endoscopy 2008; 40: 6-7

(c) Georg Thieme Verlag KG Stuttgart · New York . ISSN 0013-726X

Corresponding author

\section{K. Tanaka, MD}

Department of Endoscopic Medicine Mie University School of Medicine 2-174 Edobashi

Tsu

Mie 514-8507

Japan

Fax: +81-59-231-5200

kyosuket@qa2.so-net.ne.jp 